\title{
Personal experiences of Autism and secure units
}

\begin{tabular}{|r|l|}
\hline Journal: & Advances in Autism \\
\hline Manuscript ID & AIA-04-2016-0010 \\
\hline Manuscript Type: & Case Study \\
\hline Keywords: & $\begin{array}{l}\text { Autism, Forensic, Offending behaviour, Learning Disability, Challenging } \\
\text { Behaviour, Criminal Justice System }\end{array}$ \\
\hline \multicolumn{2}{|l}{} \\
\hline
\end{tabular}

\section{SCHOLARONE $^{\text {m }}$ \\ Manuscripts}




\section{Personal experiences of Autism and secure units}

In the first of a series of articles on perspectives on autism care we talk to Dr Sanjib Ghosh about his experience of working with people with autism in secure care. Dr Ghosh is a Consultant Psychiatrist who tells us about some of the practice issues and concerns for clinicians working with people with autism in secure care and includes comments on the issues raised by one individual with autism (who has consented to sharing his thoughts) in secure care based in their experiences. This is particularly relevant given the recent publication of the Building the Right Support, which offers national guidance to develop community services and close inpatient facilities for people with a learning disability and/or autism who display behaviour that challenges, including those with a mental health condition.

For many a diagnosis of autism is made in childhood. For others a diagnosis occurs in adulthood. For this group often autism has gone undetected and prevented them from getting the support they require. For many it is only following a crisis that a diagnosis is made. Many who are unaware of their autism, once diagnosed are able to retrospectively report how it has affected and behaviours that have led to them being admitted to secure care. Many of those with autism report that their behaviour from an early age has got them into trouble and into contact with both the police and secure hospital services. As part of looking at current provision below is an insight into a person diagnosed with autism as a child, currently in secure care. As a child he was unaware of having autism but knew that his behaviour led to him getting into trouble. Below is an insight

One of the problems I have struggled to control in the past is being repetitive and touching people. As an adult I have also got into trouble after drinking, often due to disagreements that have ended at times in fights. I have spent long periods in hospital being sent there from the Court. Once you have got into trouble and find yourself at the police station it can be very difficult. For one it is hard to fathom out what is going on, what is expected of you and what happens next. In the police station it is difficult to concentrate due to the noise. Although there are people who meet you there such as the solicitor and an appropriate adult, I have found that no one tells you what is going to happen in a way that is easy to understand. Often what is said does not make sense. Once you are in the police station people, especially the police staff, do not treat you normally anymore. Instead they become stricter with you. This is the same I have found when I have had to go to court.

The last time I was in court I was sent to hospital to help with my behaviour. This I was told was necessary before I could live again in the outside world. Although many people feel hospital is not the best place for people with autism at the moment, it is helping me towards going back to live in more normal and familiar surroundings. Which hospital you will end up in is often a mystery! For example is it a NHS or an 
independent hospital? How secure will it be? What are the rules? Even in the same levels of security the rules and what you can do are different. At the moment the service I am in is trying to give me the help I need to go home. In the past I have been to a number of specialist secure services including those that treat people with autism. This is frustrating as in the past few years I have been regularly moved between services. Much of this is because of changes that are thought to be necessary following Winterbourne View. As a result of this I am on my third move as the places I have been sent have been closed down before my treatment can finish. I am told this is not because of me but changes in policy. However in recent years I have changed hospital three times. It is always difficult going to a new place although they offer the same service they are not the same. For example the people are different the layout is different the treatment is different the rules are different. I could go on but these type of issues are a big deal to me and I think I would have left hospital by now if I was allowed to stay just in one place. With every move comes challenges and often it seems I am starting again and difficult to believe an end is in sight. In the hospitals I have been in I have not noticed any differences between those that say they are specialist autism or autism friendly to other types of services. Often they will be noisy from time to time and pressure you to join in with things when you are not feeing up to it. What makes the difference and a good service in my opinion is when people are able to support you and give you space to do your own thing or just be on your own sometimes.

Having autism means that in everyday life often people treat you differently. This includes how they talk to you, approach you and act around you. I enjoy mixing with people to do things I like such as snooker. On the ward we will play 2 vs 2 but at the same time I like to have my own pace in my room and not be bothered. At the moment I am looking forward to the future I have a meeting coming up soon to discuss my progress and how near I am to or what I need to achieve before I can be discharged. Since being in hospital my plans have changed. Important to me are my family and I look forward to my visits with my sister. Hopefully I can be discharged to a hostel where I can have visits and be close to my family. At the same time I would like there to be a good support package in place to help me with things I find difficult, and to help keep me out of trouble with others.

For Dr Ghosh this insight highlights practice issues and concerns for clinicians working with people with autism in secure care. Below is an insight to a psychiatrists perspective of these issues and offers an insight into the support and treatment received in secure care.

$\mathrm{Xl}$ is a well-liked and friendly person on the ward. He is a committed resident of the ward participating and leading in activities as well as his job, which is currently helping with cleaning tasks on the ward. He has had ups and downs. We share his concerns he could become too comfortable with a ward environment as he has spent a 
number of years in hospital. That is why good participation in activities on the ward, and later outside the ward is important. Despite set-backs in the past, he has worked hard and is in one of his most productive spells. He has earned his increasing escorted community leave and used it well. Our next steps together will focus on using that leave to do activities, which he can continue into the community.

Although we recognise diagnoses as important, they represent only one aspect of a person. We see each patient as a fellow human being and member of the ward. This allows us to build relationships with them to engage in our program. Breaking the stigma which labelling can bring is nevertheless a responsibility, which even as mental health professionals, we need to remind ourselves of.

The characteristics of patients with Autism will vary depending upon their age, developmental level and how severely they are affected. The difficulties can change over time. There are no known cures for autism. Our focus is on providing information about the condition and managing difficulties. Overall, the problems and behaviours can be divided into three main areas: communication, behaviours and social interactions.

With respect to communication, we try to keep information simple and with predefined vocabulary familiar to all of us. $\mathrm{X}$ has developed his communication skills. A key area he identified early on, and in his account in this article, was that he can be repetitive in what he says. He made a lot of changes in this area to the point that this problem is barely noticeable. It also shows the role of insight and motivation of the patient to bring about meaningful change, as opposed to simply following externally imposed "box-ticking" programs. One-to-one time with a dedicated Speech and Language Therapist has been useful for him. Engaging in groups has given him abilities to lead and listen through discussions. Likewise, we as staff are continually learning to adapt our communication style to make our sessions involving patients more useful. Sometimes during time-pressured ward rounds we can slip into the comforts of medical jargon. X will sometimes amicably allow us to continue and indicate he is following the conversations. However, we therefore check his understanding of issues as a means of measuring how effective our communication has been. On those occasions he has not understood much, it often may indicate we need to invest more time explaining to him and put more thought into the words we use. Besides this, $\mathrm{X}$ has felt more at ease helping us improve in our ability to communicate through telling us if he has not understood. Doing education work on literacy and numbers has helped increase his use of language and provided qualifications demonstrating tangible progress. He has also worked hard in understanding his own emotions and others.

Through a better understanding of how others feel, he has also learnt to adapt his behaviour. X questioning and reducing some previous problematic behaviours, particularly touching and occasionally assaulting others, has been important. We have had problems in the past with patients including $\mathrm{X}$ being aggressive to others, and 
suffering from others' aggression. We have found increasing the activities on the ward, and using social therapists to lead some, have helped decrease this. Addressing this in community meetings has helped as well. To manage difficulties we have used medications. We would not use medications for autism without complications. We always aim for the lowest, most effective dose. X finds they have helped him stay calm and his views have been critical in making our choices. His occupational therapy-led activities and psychology-led behavioural plans have also incentivised him to stay engaged and aim to get out of hospital and stay out.

Working on communication and behavioural difficulties also helps with respect to social interactions. Family and friends are crucial for most people, and it is no different for X. His mother and sister in particular take a great interest. Their contact with him varies from daily phone calls, regular letters and frequent visits. They give us useful background information and provide a number of insights into what has helped him previously. With X's permission they also includes suggestions we incorporate. They have been feeding back positive progress in their relationship. They will also inform us of areas they feel we can focus improvements on. A number of $\mathrm{X}$ 's activities and outside trips are planned involving his family when they request it. At the same time, we respect his interest in his own company, and leave him space to be alone. We try to encourage social interaction without being prescriptive.

Within a secure setting, the balance between the individual rights of the patient and public protection is often a core issue. This is no different for X's presentation. As he says in his account, he has had continuous problems with touching people with some incidents escalating to fights. He has used relatively low level but frequent inappropriate behaviours and violence. This has led to problems in the community where he can become a risk to others, and at risk from others by way of retaliation. It has led to him being admitted to hospital. Over time, the behaviours have been found too challenging for open wards, and he has required higher levels of secure settings to be managed. This involves more staff and more restrictions on what one can do. X illustrates a number of issues, which we as clinicians have in the past not always taken full account of. He talks about the disruption caused through changing hospitals and the prolonging effect it has on being an inpatient as one adapts to a different environment, with different rules and different staff and patients. This is even applicable to wards with similar levels of security. He mentions how some hospitals have been closed down and he has had to be transferred out before he completes his treatment program. The fact that these transfers are not driven by his clinical presentation, but by external factors, can be all the more dispiriting. The less autonomous settings, and prolonged hospital stays, can contribute to patients being institutionalised. This is one of the key concerns to have in mind for X, his family and friends, and our clinical team. Therefore, as well as focusing treatment on decreasing his level of security and moving him on to the community, we have generally resisted moving him to other places with similar levels of security. 
This makes the targeted discharge into the community a less achievable goal, particularly after a number of years. One could argue that having autism and the rigidity in routine and behaviours associated to it can make it harder to adapt well enough to be discharged into the community. Following the findings of Winterbourne view among other enquiries, this situation has become more recognised. Dedicated panels including medical experts are working on innovative solutions to fast-track these conditioned patients into a discharge pathway to supported accommodation. The success of this must surely include a judgement made by society of the type and severity of problematic behaviour it would tolerate to enable such patients to stay in the community. As X envisioned in his account, discharge to a hostel is his ultimate aim. However it would need appropriate staffing and facilities to help him stay out of trouble and get on with his life and aspirations in the community. 